\title{
O IZVAJANJU GLASBE
}

Ključne besede: estetika glasbe, Peter Kivy, izvajanje glasbe, skladateljeve intencije, historično avtentično izvajanje

\section{Uvod}

V svojem delu Authenticities: Philosophical Reflections on Musical Performance ameriški filozof in muzikolog Peter Kivy govori o glasbenem izvajanju, in sicer na nivoju kritike historično avtentičnega izvajanja. Ta del Kivyjeve estetike ${ }^{25}$ je eno od redkih mest, kjer je filozofska pozornost sistematično namenjena nivoju izvajanja, saj se tradicionalna filozofija $\mathrm{z}$ izvajalskimi umetnostmi ni dosti ukvarjala. Kivy močno problematizira nekatera ustaljena in kot se izkaže, velikokrat nepreverjena in neutemeljena stališča. Problemi, ki jih poudarja, ki jih najprej poskuša identificirati in nato pokazati na alternativno možnost njihovega razumevanja, so nekateri glavni problemi sodobnega izvajanja klasične glasbe. Velika zasluga Kivyje diskusije o izvajanju je v tem, da odpira nove poglede na nekatera temeljna

25 V svojem obsežnem opusu Peter Kivy sistematično obravnava nekatere poglavitne glasbene teme: emocije, reprezentacijo, razumevanje, užitek, vprašanje vrednosti glasbe kot umetnosti, raven izvajanja, idejo genija in podobno. Veliko pozornosti namenja instrumentalni glasbi 18. in 19. stoletja in išče možnosti za neko konsekventno razlago čiste glasbe, ki je v filozofiji in estetiki glasbe svojevrsten teoretični izziv. Razvoju Kivyjeve estetike instrumentalne glasbe je moč slediti od njegovega prvega pomembnega dela s tega področja, The Corded Shell (1989), v katerem se ukvarja $\mathrm{z}$ vprašanjem glasbene ekspresivnosti, do $\mathrm{v}$ tej povezavi osrednjega dela Music Alone (1990), kjer je eksplicitno izpostavljena ideja čiste glasbe (»music alone«), ki jo avtor tudi pozneje razvija na različnih ravneh.

Estetika glasbe Petra Kivyja nadaljuje linijo formalistične tradicije teoretiziranja o glasbi, ki jo odločilno razvija in nadgrajuje. Kivyjevo pozicijo kot »razširjeni formalizem« (»enhanced formalism«), opredeli Philip Alperson. »Razširjeni« formalizem zato, ker glasba ni pomembna zgolj zavoljo svojih formalnih kvalitet, ampak tudi zaradi drugih estetskih kvalitet, med katerimi so še zlasti pomembne ekspresivne. 
vprašanja izvajalske prakse, kar izvajalcu vsekakor omogoča boljše razumevanje svoje vloge znotraj glasbenega življenja.

Historično avtentična izvajalska praksa nastane na podlagi muzikološkega preučevanja starih načinov in praks izvajanja, ki si postavlja za cilj rekonstrukcijo glasbe, kot so jo prakticirali v preteklosti. ${ }^{26}$ Po Kivyjevem mnenju gre pri tem za pojav, ki presega zgolj historični interes in motivira oblikovanje nove izvajalske estetike oziroma močno posega v predstavo o tem, kaj naj bi v zahodnem kulturnem prostoru izvajanje pomenilo. Bistvo ideje o historično avtentičnem izvajanju namreč temelji na stališču, po katerem pomeni način izvajanja samega skladatelja ali izvajalcev, ki so bili del glasbenega življenja skladateljeve dobe, tisti optimalni način izvajanja.

\section{Izvedba v skladu s skladateljevimi intencijami o izvajanju}

Ko imamo pred sabo partituro, glasbeni zapis, ki ga želimo izvajati, smo pri problemu interpretacije glasbenega dela. Kako izvajati neko glasbeno delo, ali kot zdaj pogosto zasledimo formulirano to vprašanje, kako ga izvajati na avtentičen način? Kot se izkaže, je meril za avtentičnost izvedbe več. Najpogostejše vprašanje, ki se postavlja izvajalcu, je verjetno, kaj je hotel skladatelj, kako si je predstavljal zvočno podobo svojega dela, kakšna je bila zanj idealna predstava, idealna izvedba? Ker so bili skladatelji pogosto tudi izvajalci, velikokrat virtuozi, se izvajalcu porajajo še bolj vznemirljive spekulacije: kako je skladatelj sam igral svoja dela? Kako je Beethoven igral svoje klavirske sonate? Kako je Bach izvajal Matejev pasijon v Tomaževi cerkvi v Leipzigu? ${ }^{27}$

Skladateljeve intencije o izvajanju so bodisi eksplicitno izražene v partituri ali pa nanje lahko sklepamo iz izvajalske prakse skladateljevega obdo-

26 Tovrstno raziskovanje usmerja svojo pozornost tako na zgodovino izdelovanja instrumentov in vprašanje njihove uglasitve kot na sestave izvajalskih skupin, na izvajalske in pevske tehnike, na vprašanja fraziranja, okraševanja itd.

27 Skladatelji imajo do načina izvajanja svojih del lahko zelo različen odnos. Debussy je bil primer zelo liberalnega skladatelja, ki je sebe štel le za enega od možnih interpretov svoje glasbe. Nasprotno je Händel menda iztrgal Corelliju violino iz rok, da bi mu pokazal, kako naj igra njegovo delo. 
bja. ${ }^{1}$ Kivy najprej opozarja na samo izbiro izraza »intencija « za skladateljeve napotke o izvajanju, ki implicitno sugerira način njihovega razumevanja. Izkaže se namreč, da je pomen, v katerem lahko izraz smiselno uporabimo, predvsem pomen zahteve. Lahko rečemo: jaz nameravam igrati na ta način, ne moremo pa reči, jaz nameravam, da ti igraš na ta način. Lahko rečemo le jaz hočem ali jaz zahtevam, da igraš na ta način. Izbira izraza posredno kaže na stališče, da imajo vse skladateljeve intencije enako težo, da jim pripada moč zahteve. V bistvu pa ni moč trditi, da so vsi skladateljevi napotki intencije v strogem pomenu, v smislu zahteve, lahko so zgolj predlogi, usmeritve ali želje. V tem smislu je njihovi realizaciji zavezan tudi izvajalec. $^{2}$ Tudi Stephen Davies zato ločuje med »determinativnimi intencijami«, ki so relevantne za sodbe o avtentičnosti, in med "priporočilnimi intencijami« (Davies, 1987, 39) - slednje niso odločilne za delo samo, njihova realizacija zato ni nujna. Ugotovitev o različni moči intencij vodi $\mathrm{k}$ vprašanju, katere intencije sodijo v posamezno kategorijo, ki je historične narave in zahteva muzikološke raziskave.

Intencije o izvajanju so vsekakor pomembno merilo izvajanja. Poznavanje načina izvajanja skladatelja in prakse izvajanja skladateljeve dobe, kolikor jo historično raziskovanje zmore rekonstruirati, je danes pomembna, če ne celo nujna informacija za izvajalca. Zato se vprašamo, kdaj lahko rečemo, da se jim je izvajalec približal, in kdaj lahko trdimo, da jih je kršil? Kdaj je izvedba avtentična, ker je v skladu s skladateljevimi intencijami o izvajanju? Kivy se tega vprašanja loteva na način analize koncepta intencije. Intencije so podobno kot želje del našega vsakdanjega življenja, zato tisto, kar velja za intencije na sploh, velja tudi za skladateljeve intencije o izvajanju. »Skladatelj je bil človek, ne historični artefakt« (Kivy, 1995, 39).

Poglejmo nekatere glavne dejavnike, ki določajo koncept intencije. Eden pomembnih je kontekstualnost: tisto, kar si nekdo želi ali hoče, je relativno glede na možnosti, ki so na razpolago, saj se z novonastalimi razmerami izbire spreminjajo. Pri tem je treba upoštevati tudi možnosti, ki so

1 Na nivoju tega vprašanja se tako prepletata avtentičnost intencije in izvajalske prakse.

2 V skladu s Kivyjem v nadaljevanju izraz »intencija « za skladateljeve napotke o izvajanju uporabljam kot umetniški termin, ki obsega vse skladateljeve napotke, ne glede na pomen, ki ga intencija nosi. 
zgolj hipotetične. V takem primeru gre za "preddejanske intencije» (Kivy, 1995, 34), za želje in hotenja, ki jih preko aktualnih pogojev usmerjamo v prihodnost, v nove, zgolj predpostavljene okoliščine. Vprašanje je torej, ali bi Bach danes vztrajal pri »starih « pogojih ali bi ponovil svojo prvotno izbiro instrumentov za izvajanje svojih del. To je sporno še zlasti zato, ker je bil, kot je znano, zelo naklonjen izboljšavam instrumentov. ${ }^{3}$ Zato ne moremo $\mathrm{z}$ gotovostjo trditi, da svojih del ne bi želel izvajati na modernih instrumentih, $\mathrm{z}$ večjimi orkestri ali v moderni koncertni dvorani. Po mnenju Stephena Daviesa je »včasih mogoče iz tega, kar je zapisano v partituri, sklepati, da bi skladatelj raje napisal kaj drugega, če bi bili instrumenti ali izvajalci sposobni ugoditi njegovim intencijam « (Davies, 1987, 43). Seveda na drugi strani ne moremo zagotovo vedeti, ali bi bil Bach zadovoljen s sodobnimi instrumenti in koncertnimi dvoranami. Morda bi bil zgrožen ob dejstvu, da se njegova liturgična dela izvajajo zgolj za estetki užitek.

Analiza intencije tukaj kaže na stališče, da bi drugačne okoliščine povzročile spremembo vsaj nekaterih skladateljevih izbir. S tem Kivy pokaže, da skladateljeve intencije, ne glede na to, ali jih razumemo kot zahteve ali kot zgolj sugestije, niso apriori tiste idealne, kot to trdijo zagovorniki historično avtentičnega izvajanja. Vprašanju, kaj je Bach hotel leta 1724, zato legitimno sledi vprašanje, kaj bi hotel v nekih novih razmerah za izvajanje. »Kakšne bi bile Bachove intencije o izvajanju danes, v okoliščinah, v katerih danes ustvarjamo glasbo, je del njegovih intencij o izvajanju, čeprav nikakor ni mogel predvideti, kakšno bo glasbeno življenje v enaindvajsetem stoletju « (Kivy, 2002, 134). Kako jasni bodo odgovori, je po Kivyjevem mnenju v splošnem odvisno od kulturne razlike med takratnimi in novimi okoliščinami.

Izredno pomemben dejavnik intencij je njihova hierarhičnost. Kivy tukaj izhaja iz dela Randalla Diperta. Dipert pravi, da moramo poznati hierarhijo skladateljevih originalnih intencij, da bi lahko dognali, kateri način bi skladatelj zasledoval v novih okoliščinah; »reinterpretacija želj in intencij pod drugačnimi pogoji bo odkrila nove možnosti za skladatelja ...« (Kivy, 1995, 43). Kivy kot primer navaja Bachov Brandenburški koncert št. 2. In-

3 Kivy navaja Bachovo pismo, v katerem je predložil število instrumentov, ki so potrebni za izvedbo njegovih del. Če bi bile okoliščine ugodnejše, bi bile Bachove zahteve verjetno večje. 
strumenti, ki jih je Bach izbral, so trobenta, angleška flavta, oboa in violina. Kivy sklepa, da je Bach izbral te instrumente, ker je zasledoval posebno barvo tona in dinamično ravnovesje, saj vsak instrument izvaja enakovredno, samostojno linijo. Izvedba na starih instrumentih pokaže, da se ravnovesje med instrumenti poruši; flavte v spodnjih registrih skoraj ni slišati. Izvedba na modernih instrumentih izboljša ravnovesje, vendar se močno spremeni barva tona; na nivoju dinamične enakovrednosti gre za izboljšavo, na nivoju barve tona pa za močno spremembo.

Dipert govori o dveh nivojih skladateljevih intencij: o »visokem nivoju « in "nizkem nivoju « intencije. Prvi nivo ponazarja estetski efekt, ki ga skladatelj zasleduje pri svojem delu; Bach je hotel barvo tona in enakovrednost instrumentalnih linij. Drugi nivo intencij je v zvezi s samo realizacijo intendiranega estetskega efekta; gre za sredstva, s katerimi ga dosežemo. Po Dipertovem mnenju je visok nivo intencij tisti, ki ga je treba najprej določiti, da lahko oblikujemo drugi nivo. Oboje ni nujno združljivo, Kivy dopolnjuje Diperta, kar dokazuje zgornji primer. Izvajalec se mora odločiti, kaj je bila Bachova prioriteta, saj kot smo videli, obojega ni mogoče realizirati hkrati. Če bo izvajalec presodil, da je bila Bachova prioriteta barva tona, bo izvajal na starih instrumentih, če bo nasprotno predvideval, da je dinamično ravnovesje tisto, kar je Bach zlasti hotel, bo uporabil moderne instrumente. Pri izvajalčevi odločitvi o tem, kaj je bila Bachova prioriteta, sodeluje tudi izvajalčeva lastna estetika. Določanje "visokega nivoja« intencij je namreč del interpretacije glasbenega dela, ki je »... prvi pogoj za odločitev, kakšen način izvajanja bi se najbolje skladal s skladateljevimi željami in intencijami - kar pomeni, kakšen način izvajanja bi bil, glede na sedanje razumevanje, historično avtentičen " (Kivy, 1995, 45). Iz tega sledi, da iskanje avtentičnosti intencije vključuje tudi sodbo okusa, da je hkrati del naslednjega odločujočega cilja, realizacije dobre izvedbe. ${ }^{4}$

4 V tej zvezi je zanimivo ugotavljanje Jurija Snoja, ki v svojem zapisu med drugim obravnava tudi Kivyjevo estetiko izvajanja: »Ob nekaterih historično avtentičnih interpretacijah se vzbuja vtis, da so bolj kot interpretacije glasbenih del poskusi rekonstruiranja glasbenih dogodkov preteklosti. Zdi se, da si ne zastavljajo vprašanja, kako interpretirati glasbeno delo, npr. Matejev pasijon, srednjeveško liturgično dramo, pač pa kako čim bolj verno rekonstruirati pretekli glasbeni dogodek, npr. srednjeveško uprizoritev liturgične drame. Koncert s tako izvedbo postavlja sodobno publiko predvsem v vlogo opazovalca uprizoritve obnovljenega koncerta iz preteklosti in šele v drugi vrsti ji omogoča, da spremlja interpretirano 
Kot pokaže Kivy, zgolj realizacija skladateljevih eksplicitnih in implicitnih intencij ni zadosti, da bi lahko na podlagi merila intencije govorili o avtentični izvedbi. Skozi analizo koncepta intencije se kaže pomembnost interpretativnega elementa pri njihovem razumevanju oziroma realizaciji. Kivy zasleduje razumevanje intencij, ki vključuje tudi spontanost in ustvarjalnost, brez katerega si izvajanja ne moremo predstavljati. Torej ne gre za zgolj kompromis med prisilo intencije in anarhijo okusa, ampak za njuno vzajemnost. Na podlagi Kivyjevih dognanj je moč trditi, da z izbiro modernih instrumentov ne delujemo nujno proti Bachovim intencijam, prav nasprotno, tudi na ta način jim lahko zelo dobro sledimo in realiziramo merilo avtentičnosti izvedbe. Kot pravi Roger Scruton, so izvedbe Glenna Goulda močno odmaknjene od tistega, kar bi dopuščali specialisti za "staro glasbo«, vendar so nastale, da bi sledile Bachovim idejam, »Bachovi glasbeni inspiraciji« (Scruton, 1997, 444).

Na nivoju skladateljevih intencij, ki predstavljajo enega od možnih meril avtentičnosti, se izkristalizira zelo pomembna ugotovitev, da namreč nekaj takega kot "avtentična izvedba" ne obstaja, ali kot pravi Kivy, "ni ene avtentičnosti« (Kivy, 1995, 79). Obstaja več izvedb, ki dosežejo avtentičnost na različne načine. Podobno stališče zagovarja tudi Stephen Davies. »Torej idealna avtentična izvedba nima partikularnega zvoka, ker ni partikularna izvedba. Standard, proti kateremu se avtentičnost izvedbe dela sodi, vsebuje niz izvedb, med katerimi je vsaka zvesta skladateljevim determinativnim intencijam«(Davies, 1987, 45).

Ko Roger Scruton govori o izvedbi, poudarja pomembnost nenehnega dialoga med skladateljem in izvajalcem, dialoga, ki se odvija skozi generacije in $\mathrm{v}$ katerem oba, kljub veliki časovni distanci, ki lahko obstaja med njima, igrata enako veliko vlogo. Lahko bi rekli, da je vsebina skladateljevih nekdaj izraženih intencij o izvajanju predvsem vir za izvajalčeve najboljše predpostavke, najboljše aktualne rešitve, ki jih oblikuje glede na vse razpoložljive vire. Izhaja iz strukture dela, iz poznavanja skladateljeve osebnosti oziroma historičnega okvira glasbenega okolja, v katerem je delo nastalo, kot iz lastne estetike. Avtentična izvedba je torej izvedba, v kateri izvajalec

delo samo, včasih pa ji s tem, ko se osredotoča na obnovitev glasbenega dogodka, poslušanje kompozicije celo otežuje» (Snoj, 2002, 16). 
realizira lastno vizijo izvajanja, s katero poskuša na svojevrsten, umetniško ustvarjalen način dognati, kako bi se skladateljeva hotenja razvila v na novo nastalih okoliščinah.

Realizacija intencij o izvajanju je problematična, ker se dotika vprašanja ohranitve identitete dela. Ali je ogroženo samo glasbeno delo, če uporabljamo novejše instrumente, če izvedba močno odstopa od predpisanega tempa ali artikulacije?

Vprašanje realizacije intencij o izvajanju prinaša na površje razumevanje razmerja med delom in izvedbo. Izvedba kot produkt je glasbeno delo ali instanca dela in izvajanje kot dejavnost je dejavnost, ki naredi glasbeno delo dosegljivo za poslušalca. Kot smo videli, Kivy poudarja nujnost razlikovanja med intencijami, ki imajo moč zahteve, in na drugi strani tistimi, ki so bolj usmeritve ali želje. Iz tega sledi, da je realizacija nekaterih skladateljevih intencij bolj odločilna za ohranitev dela. Vendar Kivy poudarja, da naša intuicija $v$ zvezi $z$ vprašanjem, ali so skladateljeve intencije - intencije $\mathrm{v}$ strogem pomenu - konstitutivni del glasbenega dela ali ne, ni enotna. Mejo je zelo težko določiti, vendar če ne bi obstajala, o konceptu intencij o izvajanju verjetno sploh ne bi govorili. Tako pa govorimo o dveh različnih ravneh: na eni strani je že konstruirano glasbeno delo, na drugi so intencije o izvajanju. Samo filozofska razlaga glasbenega dela bi lahko pokazala, da so skladateljeve intencije o izvajanju konstitutivni del glasbenega dela oziroma da to niso. Le na takšni podlagi bi lahko z gotovostjo trdili, da je njihova realizacija nujna, da je sama sebi namen. ${ }^{5}$

Skladateljevi napotki o tem, kako naj bi delo izvajali, imajo vsekakor posebno vrednost. Mnenje skladatelja je presoja eksperta, ki jo legitimira vrhunska glasbena sposobnost. Skladatelj je bil velikokrat tudi izvrsten izvajalec. S tega stališča je jasno, da se bodo kakršnikoli pomisleki v zvezi z realizacijo skladateljevih intencij izvajalcem zdeli hitro močno problematični ali celo neprimerni. Na drugi strani zahodna glasbena kultura pozna tudi tradicijo umetnosti izvajanja glasbe, znotraj katere izvajalec nastopa

5 Po Kivyjevem mnenju je tisto, kar je odločilno za ohranitev dela, predvsem njegova struktura. O tem Kivy piše že v The Fine Art of Repetition, kjer se prvič ukvarja z vprašanji izvajanja. Že tukaj Kivy ugotovi, da instrumentacija ni esencialni del identitete vsakega glasbenega dela, pomen instrumentov se kaže predvsem v njihovi zmogljivosti. 
kot samostojen umetnik. Skladatelj in izvajalec tradicionalno drug z drugim sodelujeta, del skladateljevih intencij je tudi predpostavka o izvajalčevih lastnih predlogih, to je zahteva, ki je pravzaprav vedno implicitno postavljena pred izvajalca.

Kivy v okviru kritične obravnave avtentičnega gibanja opozarja predvsem na dogmatičnost, ki jo je mogoče v povezavi s skladateljevimi intencijami zaslediti danes v svetu glasbe, na nedotakljivo avro, ki jim pripada $\mathrm{v}$ okviru teženj po avtetičnosti. Pokazati hoče, da kljub svoji očitni pomembnosti niso nekaj, kar je treba sprejeti apriori, kar je vnaprej opravičeno razmisleka in razprave. Ko beremo Kivyeve tekste, je njegova naklonjenost Bachu več kot očitna, vendar kljub temu zapiše: »Celo Bach konec koncev ni Bog« (Kivy, 1995, 172). Nalogo izvajalca v odnosu do skladatelja vidi predvsem v zasledovanju estetskih ciljev, v oblikovanju najboljše možne izvedbe. Kot vidimo, Kivy ne vidi argumentov, ki bi podprli stališče, da so skladateljevi napotki vedno pogoj za največji estetski učinek izvedbe, čeprav so velikokrat optimalno izhodišče izvajanja. Poudariti hoče, da so za tako trditev potrebni empirični argumenti, sodba okusa, kar v principu velja tudi za največje skladatelje.

\section{Avtentičnost zvoka}

Vsebina glasbenega dela nastane $\mathrm{v}$ tesnem odnosu s kompleksno zgodovinsko situacijo, ki jo lahko opredelimo z različnimi dejavniki: to so skladateljeve intencije, predhodna dela znotraj tradicije, $v$ kateri skladatelj deluje, izvajalska praksa, stanje umetniškega sveta, splošni kulturnozgodovinski okvir itd. Zavedanje o tem, da glasbeno delo prihaja k nam iz bolj ali manj oddaljene preteklosti, vodi v vznemirljivo spraševanje, kako je glasba nekoč zvenela. Kako je zvenel Matejev pasijon v Leipzigu, ko so ga prvič izvajali? Kako ga je slišal sam Bach? Zanima nas tudi, kaj so sodobniki prepoznali $\mathrm{v}$ tej glasbi, kaj jim je pomenila, kaj je predstavljala v njihovem življenju? In seveda, kako naj vrednotimo neobhodno razliko, ki obstaja v izkušnji glasbe med nami in Bachovimi sodobniki?

Tukaj nas ne bo toliko zanimal kontekst nastanka dela. Dotaknili se bomo vprašanja, kako glasbeni in kulturnozgodovinski razvoj vpliva na 
razumevanje in vrednotenje glasbenega dela. Znotraj Kivyjeve estetike se tega vprašanja lahko lotimo skozi obravnavo t. i. »vstavljenih historičnih kvalitet « (Kivy, 1995, 54), ki so povezane z delovanjem zgodovine. Da bi poslušalec lahko zaznal »vstavljene historične kvalitete«, mora biti na določeni točki v zgodovinskem razvoju glasbe. Kot paradigmatični primer za tako kvaliteto Kivy navaja začetek Beethovnove Prve simfonije; za prve poslušalce je bil šokanten in revolucionaren, zdaj ga ne moremo več slišati na ta način. Lahko se zgolj seznanimo s tem, kakšen učinek je imel na prvotne poslušalce, in tudi to povzroči svojevrsten estetski učinek, obogati izkušnjo glasbe.

Če je Beethovnova Prva simfonija izgubila neko svojo kvaliteto, na drugi strani lahko delo zaradi kulturnozgodovinskega razvoja, ki sledi obdobju njegovega nastanka, pridobi nove kvalitete. $\mathrm{V}$ tem primeru govorimo o anticipacijah; nekaj se "zgodi« pred svojim časom, recimo slutnje atonalnosti v delih pred dvajsetim stoletjem, romantične harmonije pri Bachu in podobno. Treba je poudariti, da takšnih kvalitet sodobnik dela ni mogel slišati, prav tako niso mogle nastati $\mathrm{z}$ intencijo skladatelja. Zato se postavi vprašanje, ali so take kvalitete legitimen del estetske izkušnje dela? Kivy vprašanju v splošnem liberalno pritrjuje, naša izkušnja glasbe nujno obsega take kvalitete, glasbo danes poslušamo iz historične perspektive, ki se ji ne moremo izogniti, kot poslušalci smo neizogibno "produkt zgodovine» (Kivy, 1995, 55).

Problem, ki ga takšne kvalitete prinašajo in na katerega Kivy predvsem opozarja, je, da ne moremo trditi, da je umetniška smer, ki se je zgodila v 19. stoletju, povzročila novo kvaliteto v delu, ki je bilo dokončano leta 1750. Zato jih je po Kivyjevem mnenju veliko bolje razumeti kot historično odkrite; zgodovina odkrije novo kvaliteto, ki jo je delo že ves čas vsebovalo, vendar jo lahko prepozna šele poznejša doba, izpostavijo jo nova umetniška gibanja. Jerrold Levinson se nekoliko obsežneje ukvarja s tem vprašanjem. Tudi Levinson pravi, da se vsebina umetniških del ne spreminja, govori o njeni »relativni stabilnosti in trajnosti« (Levinson, 1990, 186). »Umetniška dela niso tista, ki se v odločilnem smislu spreminjajo skozi čas, spreminjamo se mi. Mislimo več, izkušamo več, ustvarjamo več - in kot rezultat smo sposobni najti v umetniških delih več kot prej« (Levinson, 1990, 181). Levinson $\mathrm{v}$ tem okviru govori tudi o delih, ki so danes prepoznana kot 
znamenja umetniških gibanj oziroma ki so vplivala na poznejšo umetnost. Levinson v zasledovanju tega vprašanja ločuje med možnimi in opravičenimi ocenami dela $\mathrm{v}$ času njegovega nastanka in $\mathrm{v}$ času, ki nastopi po dobi, v kateri je bilo ustvarjeno; Beethoven postane znanilec romantike šele, ko to poudarijo romantiki, sodobniki nikakor niso mogli postaviti take ocene. Del Beethovnove Sonate op. 111 močno spominja na jazz. Šele naknadni razvoj jazza je omogočil, da predvsem zaradi močno sinkopiranega ritma glasba v poslušalcu zbuja tovrstne asociacije. Pasažo Sonate slišimo podobno jazzu, vprašanje pa je seveda, ali jo je smiselno prikazovati kot jazz. Levinson v tem primeru odklanja to možnost.

Na ravni historično razvitih estetskih kvalitet se pokaže "paradoks avtentičnega izvajanja ${ }^{6}{ }^{6}$ ki je hkrati paradoks historične muzikologije, pravi Kivy. Jurij Snoj piše: »Vse to glasbenozgodovinopisno raziskovanje, katerega izsledki omogočajo branje glasbenih zapisov v njihovi zvočnih in izvajalskih okvirih, si postavlja za cilj zgodovinsko čim bolj verno rekonstruiranje glasbe, kakršna je v preteklosti v resnici zvenela« (Snoj, 2002, 8).

Vendar, kako je glasba $v$ resnici zvenela? Kivy tukaj močno problematizira nekatera ustaljena, in kot se lahko izkaže nepreverjena in neutemeljena stališča. Razlikuje med »zvočno« in »senzibilno« avtentičnostjo. Prvo je v principu zelo enostavno konstruirati, veliko teže jo je realizirati v praksi. Izvedba je zvočno avtentična, če je podobna ali celo identična $\mathrm{z}$ izvedbo iz preteklosti, ki smo jo iz nekega razloga izbrali za merilo. Senzibilna avtentičnost pomeni rekonstrukcijo intencionalnega objekta poslušanja. Razlika temelji na dveh pomenih poslušanja: prvi zajema celoto zvoka, vse, kar je mogoče slišati (fizikalne motnje medija), drugi pomen opisuje zavestno

6 Kivy poudarja tudi Dantojevo formulacijo tega problema v umetnosti. Danto se izogne zgoraj navedenemu metafizičnemu problemu in pravi, da nova umetniška dela izpostavijo nove kvalitete, ki jih umetniški svet prej ni poznal. Predpostavimo, da je F kvaliteta nekaterih novih umetniških del. Hkrati ne-F postane umetniška kvaliteta vseh starih del, ki prej ni bila opažena, čeprav so jo ves čas vsebovala. Tako za neko sliko pokrajine iz 17. stoletja lahko rečemo, da je reprezentativna in neekspresionistična. Vendar do pojava ekspresionizma nihče ni mogel opaziti, da delo vsebuje to negativno kvaliteto. Nereprezentativnosti niso poznali kot mogoče poteze umetniškega dela. Umetniška dela vseskozi posedujejo negativne kvalitete, ki jih poznejše dobe, gibanja, slogi naredijo za evidentna, ko na podlagi takih kvalitet ustvarijo nova umetniška dela. Nova umetniška gibanja predvsem razširijo izrazje in obseg kritiškega jezika, ne ustvarjajo novih umetniških kvalitet. 
percepcijo, tisto, kar je pri poslušanju dejanski objekt poslušalčeve pozornosti. Kaj se pokaže iz primerjave načina poslušanja publike iz 18. stoletja $\mathrm{z}$ današnjo publiko? Naša izkušnja glasbe ni odvisna samo od splošnega družbenozgodovinskega razvoja, ampak tudi s samo zgodovino glasbe. $\mathrm{Pu}$ blika 18. stoletja je poslušala glasbo izrazito ahistorično, brez poznavanja glasbene zgodovine, glasbenih del preteklosti in tudi brez večjega interesa za to preteklost. Zdaj poslušamo Bacha s predpostavko o vsem, kar se je v zahodni glasbeni kulturi zgodilo po baroku, vse do atonalne glasbe oziroma sodobne glasbe 20. in 21. stoletja. Historično poslušanje je omogočila muzikologija s svojo raziskovalno dejavnostjo, s katero se je bistveno povečalo znanje o zgodovini glasbe. Velik del historično razvitih kvalitet je bil odkrit na podlagi historičnega poslušanja. $Z$ avtentičnim izvajanjem se pojavi nova historična dimenzija poslušanja, saj se pri avtentični izvedbi ne zavemo samo pripadnosti glasbenega dela nekemu stilnemu obdobju v zgodovini glasbe, ampak tudi zgodovinskega izhodišča samega načina izvajanja. Historično ne dojamemo samo dela, ampak tudi izvajanje.

Intencionalni objekt poslušanja prebivalca Leipziga iz 18. stoletja je bil bistveno drugačen od intencionalnega objekta prebivalca Ljubljane iz 21. stoletja. Ali torej sploh lahko dosežemo avtentično izkušnjo Bachove glasbe? Verjetno lahko realiziramo zvočno avtentičnost, vendar ne poslušamo na avtentičen način, to je ahistoričen način, kot ga je poznala takratna publika. Avtentično izvajanje torej lahko realizira zvočno avtentičnost, vendar na račun senzibilne avtentičnosti. Na drugi strani se izvajanje »mainstream« izvajalske prakse, ki celoten repertoar zahodne glasbe izvaja z modernimi instrumenti in s podobno estetiko izvajanja, po Kivyjevem mnenju bolj približa ahistorični izkušnji, saj na ta način glasbo od Bacha do aktualne sodobnosti postavi v »brezčasno sedanjost « (Kivy, 1995, 232). Torej je nekako bližje senzibilni avtentičnosti. Vidimo lahko, da iskanje avtentičnosti ne moremo omejiti samo na produkcijo zvoka na star način.

Vprašanje je, kako naj vrednotimo to razliko, ki očitno obstaja med skladateljem, njegovimi sodobniki in med publiko poznejših obdobij? Ali so sodobniki bolje razumeli glasbo ali naj si torej želimo izkušnjo glasbe »originalne publike«? Kivy izpodbija stališče, da je pozicija originalne publike ponavadi idealna. Poudarja napredek, ki ga prinaša delovanje zgodovine $\mathrm{v}$ vrednotenje umetniških del, ki ne ogroža nujno razumevanja umetno- 
sti, prav nasprotno, predstavlja konstitutivni del takšnega razumevanja. "... zaradi naše razširjene historične perspektive in glasbenoteoretičnega razumevanja, naše doumevanje in vrednotenje presega sodobnike glasbe, dokler ga štejemo kot objekt estetskega vrednotenja« (Kivy, 1995, 214-215). Sodobniki dela morda pri skladatelju prepoznajo njegove izjemne ustvarjalne sposobnosti, vprašanje pa je, ali so sposobni njegova dela tudi primerno vrednotiti, razumeti, in še zlasti, ali so sposobni sproščene izkušnje njegovih del.

\section{Izvajanje glasbe kot konstitutivni del zahodne glasbene kulture}

Tradicionalna estetika se z izvajalskimi umetnostmi ni veliko ukvarjala. V skladu s splošno usmerjenostjo tradicionalne filozofije je poudarjala predvsem moment trajnosti, ki ga je uresničevalo delo v nasprotju s procesualnostjo, ki zaznamuje izvedbo oziroma izvajanje. Izvajalske umetnosti navadno niso dosegle statusa umetnosti ali pa so bile prepoznane za slabo umetnost, njihova vloga je bila $\mathrm{v}$ primerjavi $\mathrm{z}$ umetniškimi deli, ki so izražale pristno moč ustvarjalnosti, sekundarna. Pomemben dejavnik, ki je odvračal pozornost od izvedbe, je bilo tudi avtorstvo umetniškega dela. Izvajalec ni avtor, vsaj ne v običajnem pomenu te besede, izvajalec je avtor izvedbe dela nekoga drugega. Sodobna teorija umetnosti pozna nasprotne poskuse, ki govorijo o smrti avtorja, vendar je »v glasbi in muzikologiji kult avtorja in teksta danes tako živ in veljaven kot morda še nikoli ...« (Kivy, 1995, 187). Sodobna glasba lahko zaradi tehnološkega napredka do skrajnosti manipulira $\mathrm{z}$ odnosom med skladateljem in izvajalcem, skladatelj lahko ustvarja in proizvaja zvok brez izvajalca. Vendar se ta kontekst ne zdi problematičen, glasba si s tem razširja manevrski prostor, raziskuje polje svojih izraznih možnosti, išče nove načine ustvarjanja, izvajanja in produciranja. Ideologija, na katero opozarja Kivy, pa v bistvu oži glasbeni prostor. »Umetnik je lahko samo eden ali pa je delo okrnjeno« (Kivy, 1995, 279).

$\mathrm{V}$ prispevku smo podrobneje obravnavali avtentičnost skladateljeve intencije in zvoka, vendar Kivy o avtentičnosti izvajanja razpravlja na več ravneh. Govori tudi o osebnostni avtentičnosti, na podlagi katere oblikuje 
in argumentira svoje razumevanje izvedbe glasbenega dela kot posebne vrste umetniškega dela in o avtentičnosti izvajalske prakse. V zasledovanju avtentičnosti bi namreč lahko obnovili tudi takratno okolje, v katerem so izvajali glasbo. Tu se postavi vprašanje, ki znova izziva cilje historično avtentičnega gibanja: kako daleč naj sega težnja po rekonstrukciji prejšnjih načinov izvajanja glasbe? Ali je vizualni del, ki ga predstavlja originalno okolje izvajanja, estetsko pomemben del izkušnje glasbe?

Idealna izvedba, h kateri stremi avtentično izvajanje, je izvedba, ki jo najbolj določa historično znanje. Pozicija izvajalca je pri tem naslednja: kjer historično znanje in notacija odpovesta, tam lahko izvajalec nastopi z lastnimi idejami. Takšen izid je seveda močno problematičen, saj izvajalčeva ustvarjalnost nastopa kot druga izbira, nekakšen izhod v sili zaradi lukenj $\mathrm{v}$ dosegljivosti poznavanja zgodovine. Glasbe ne moremo zreducirati zgolj na tekst, na skladatelja ali historični okvir nastanka dela, čeprav pri tem nikakor ne pristajamo na anarhijo in relativizem pri interpretaciji glasbenih del. Vprašanje načina izvajanja oziroma meril dobre izvedbe je izjemno pomembno vprašanje, ki ga je treba vedno znova postavljati. Na nivoju izvajanja se glasba odkrije kot umetniški svet, ki ga poleg trajnostnega koncepta glasbenega dela bistveno zaznamuje tudi pozitivni potencial procesualnosti, improvizacije, neponovljivosti, enkratnosti trenutka. Osrednje stališče Kivyjeve razprave je tako prepričanje o pluralnosti avtentičnega izvajanja. "Ni apriorne poti do najboljše izvedbe - je samo genij izvajalca, ki ga je preizkusilo poslušalčevo uho« (Kivy, 1995, 8).

Na ravni izvajanja se potrjuje Kivyjeva kritika reprezentativnega načina razumevanja absolutne glasbe. Kivyjevo estetiko bistveno zaznamuje vprašanje instrumentalne glasbe, pri čemer je glavna pozornost namenjena predvsem absolutni glasbi 18. in 19. stoletja. V povezavi s tem glasbenim slogom Kivy razvija idejo čiste glasbe ali bolje rečeno, možnost razumevanja instrumentalne glasbe kot zvočne, ekspresivne strukture, brez zunajglasbene vsebine; zunajglasbena vsebina je $\mathrm{v}$ instrumentalni glasbi lahko navzoča zgolj potencialno in je zato irelevantna. V ozadju teženj po historični avtentičnosti Kivy prepoznava lingvistični model razumevanja absolutne glasbe, ki temelji na predpostavki o »sporočilu«, ki ga glasba vsebuje in ki se mu želimo približati. S tega stališča ni presenetljivo, da obstaja močan dvom o delu izvajalca, ki z lastnim ustvarjalnim prispevkom svoje estetike in hi- 
storične perspektive lahko pokvari »sporočilo» glasbenega dela. Opazimo lahko, da v tem primeru primarni cilj interpretacije umetnosti ni estetski. Po Kivyjevem mnenju je glavna naloga, ki je postavljena pred izvajalca, izrazito estetske narave: na najboljši možni način oblikovati in razkrivati dekorativno strukturo glasbenega dela. ${ }^{7}$

Kako bodo izvajali v prihodnosti, saj bo večina del ne samo zapisana, ampak tudi posneta. Bodo vsi pripravljeni igrati na enak, vnaprej predpisan način? Poznavanje zgodovine glasbe in starih načinov izvajanja je nekaj, kar dela svet glasbe pestrejši in zanimivejši. Muzikološka dognanja so nesporno odločilno prispevala $\mathrm{k}$ razvoju izvajalske prakse, v tem je njihova velika zasluga. Različne edicije partitur, ki predlagajo tudi način izvajanja, so nujne, vendar muzikološkega prispevka ne moremo sprejeti na račun umetniške ustvarjalnosti. Na tej podlagi Kivy formulira naslednje vprašanje: ali želimo zahodno glasbeno kulturo še naprej razumeti in razvijati kot izvajalsko umetnost? Ali naj se glasba kot umetnost skrči na skladatelja in delo? Z izgubo izvedbe bi izgubili posebno vrsto umetniškega dela. Avtentično gibanje implicitno izraža nenaklonjenosti do izvajalca. V tej zvezi je zelo zgovoren poziv, ki ga je mogoče pogosto zaslediti v tovrstnih razpravah o glasbi, "naj glasba govori sama zase«, kar pomeni, naj se izvajalčev prispevek zmanjša. Paradoksalno se težnja po ohranjanju "glasbe same« na koncu izkaže kontraproduktivna za enega od njenih konstitutivnih elementov, za izvajanje. Zapostavljanje estetskih argumentov v razumevanju glasbe je lahko $v$ skrajnem primeru destruktivno do posebne vrste umetniškega dela, do glasbene izvedbe. Izvedba glasbenega dela kot njegova "verzija« (Kivy, 1995, 134) ni nekaj destruktivnega za razumevanje in ohranjanje dela, prav nasprotno, je nekaj, kar je avtentično glasbeno.

7 Kivy prvič izpostavi dekorativnost kot alternativni model razlage absolutne glasbe v svojem delu The Fine Art of Repetition. Značilna poteza, ki bistveno zaznamuje čisto glasbo kot dekorativno umetnost, je ponavljanje; repeticije v glasbi predstavljajo njeno »definicijsko potezo«. 


\section{LITERATURA}

Alperson, P. in drugi, What is Music?: An Introduction to the Philosophy of Music, Pennsylvania, 1987.

Bent, M., Tonal Structure in Early Music, v: Criticism and Analysis of Early Music, (ur. Collins Judd, C. ), New York in London, 1998.

Bowman, W. D., Philosophical Perspectives on Music, New York, 1988.

Carroll, N., Philosophy of Art, London in New York, 1999.

Dahlhaus, C., Estetika glasbe, Ljubljana, 1986.

- The Idea of Absolute Music, Chicago in London, 1989.

Danto, A. C., After the End of Art, Princeton, 1995.

Davies, S., Musical Meaning and Expression, Itaca in London, 1994.

- Musical Works \& Performances: A Philosophical Exploration, New York, 2001.

- Authenticity in Musical Performance, British Journal of Aesthetics 27, (1987), str. 39-50.

Debeljak, A., Na ruševinah modernosti, Ljubljana, 1999.

Goehr, L., The Imaginary Museum of Musical Works: An Essay in the Philosophy of Music, Oxford, 1992.

Goodman, N., Languages of Art: An Approach to a Theory of Symbols, London, 1969.

Hanslik, E., O muzički lijepom, Beograd, 1977.

Hribar Sorčan, V. in drugi, Vstop v estetiko, Ljubljana, 2005.

Kant, I., Kritika presodne moči, Ljubljana, 1999.

Kivy, P., Speaking of Art, The Hague, 1973.

- The Seventh Sense: A Study of Francis Hutcheson's Aesthetics and Its Influence inEighteenth-Century Britain, New York, 1976.

- The Corded Shell: Reflections on Musical Expression, Princeton, 1989.

- Sound and Semblance: Reflections on Musical Representation, Princeton, 1984. 
- Osmin's Rage: Philosophical Reflections on Opera, Drama, and Text, Princeton, 1988.

- Sound Sentiment: An Essay on the Musical Emotion, Philadelphia, 1989.

- Music Alone, Philosophical Reflections on the Purely Musical Experience, Ithaca in London, 1990.

- The Fine Art of Repetition: Essays in the Philosophy of Music, Cambridge,1993.

- Authenticities: Philosophical Reflections on Musical Performance, Itacha, 1995.

- Philosophies of Arts: An Essay in Differences, New York, 1997.

- New Essays on Musical Understanding, New York, 2001.

- The Possessor and the Possessed: Handel, Mozart, Beethoven, and the Idea of Musical Genius, New Haven \& London, 2001.

- Introduction to a Philosophy of Music, New York, 2002.

- On Historically Informed Performance, British Journal of Aesthetics 42, (2002), str. 128-144.

Kivy, P., in drugi, Essays on the History of Aesthetics, Rochester, 1992.

Langer, K. S., Philosophy in a New Key, Cambridge, 1942.

Levinson, J., Music, Art, and Metaphysics, Itaca in London, 1990.

Scruton, R., The Aesthetics of Music, New York, 1997.

Snoj, J., Glasbeno delo in njegove interpretacije, Muzikološki zbornik XXXVIII, (2002), str. 5-17.

Šuvaković, M., Prolegomena za analitičku estetiku, Novi Sad, 1995.

Taruskin, R., On Letting the Music Speak for Itself: Some Reflections on Musicology and Performance, Journal of Musicology 1, (1982), str. 338-349.

Thom, P., For an Audience: A Philosophy of the Performing Arts, Philadelphia, 1993.

Wollheim, R., Art and Its Object: An Introduction to Aesthetics, New York in Evanston, 1968. 


\section{ON THE PERFORMANCE OF MUSIC}

Keywords: aesthetics of music, Peter Kivy, music performance, composer's intentions, historically authentic performance

\section{Abstract}

The American philosopher and musicologist Peter Kivy discusses musical performance at the level of a critique of historically authentic performance, which was created based on comprehensive musicological research into past performance practice. Such performance approaches originate from the belief that the performance practice of the composer himself, or of the performers that lived in the same period as the composer, is the preferred performance style. However, it has turned out that these inclinations towards authenticity contrast greatly with performers' goals, which means that they also contradict the understanding of western classical music as the art of performance. Performers try to add their own touch to the performance of a musical work; they incorporate their own perspective and esthetics in their understanding of the work and try to use an original approach, whereas the authentic performance movement in principle demands that they imitate someone else's performance.

Kivy discusses the authenticity of performance at the level of the composer's intentions, sound, performance experience, and personal authenticity. The highlighted elements contain inner discrepancies that greatly problematize these criteria of authenticity because it is almost impossible to realize all of them in a single performance. Kivy understands historically authentic performance as merely one of a number of possible interpretational approaches. Thus, the central viewpoint of Kivy's discussion is the plurality of "authentic" performance.

At the level of performance, Kivy's critique of the representative method of understanding absolute music is confirmed, because such an understanding can lead to the neglect of esthetic criteria in the interpretation of music. This article defends the viewpoint that the performance of a musical work is not something that is destructive to the understanding and preservation of a musical work, but something that is authentically musical. 